identifies these molecules as specific cell-surface ligands for DNAM1.

The killing of untransfected CHO-K cells by the NK-cell line NK92 depends on NKp30 (another orphan receptor). But, when these cells were transfected with the gene encoding PVR or nectin-2, NK-cell killing could only be partly inhibited by an NKp30-specific antibody, with the remainder of the cytotoxic activity being inhibited by an antibody specific for DNAM1. The functional interaction between DNAM1 and PVR and/or nectin-2 was also shown to lead to NK-cell activity for tumour target cells. These experiments showed that the killing of tumour cells by polyclonal NK cells depends on many triggering receptors, with the relative contribution of DNAM1 binding to PVR or to nectin-2 depending on the tumour type and ligand/receptor availability.

Kirsty Minton

(2) References and links ORIGINAL RESEARCH PAPER Bottino, C. et al. Identification of PVR (CD155) and Nectin-2 (CD112) as cell surface ligands for the human DNAM-1 (CD226) activating molecule. J. Exp. Med. 198, 557-567 (2003)

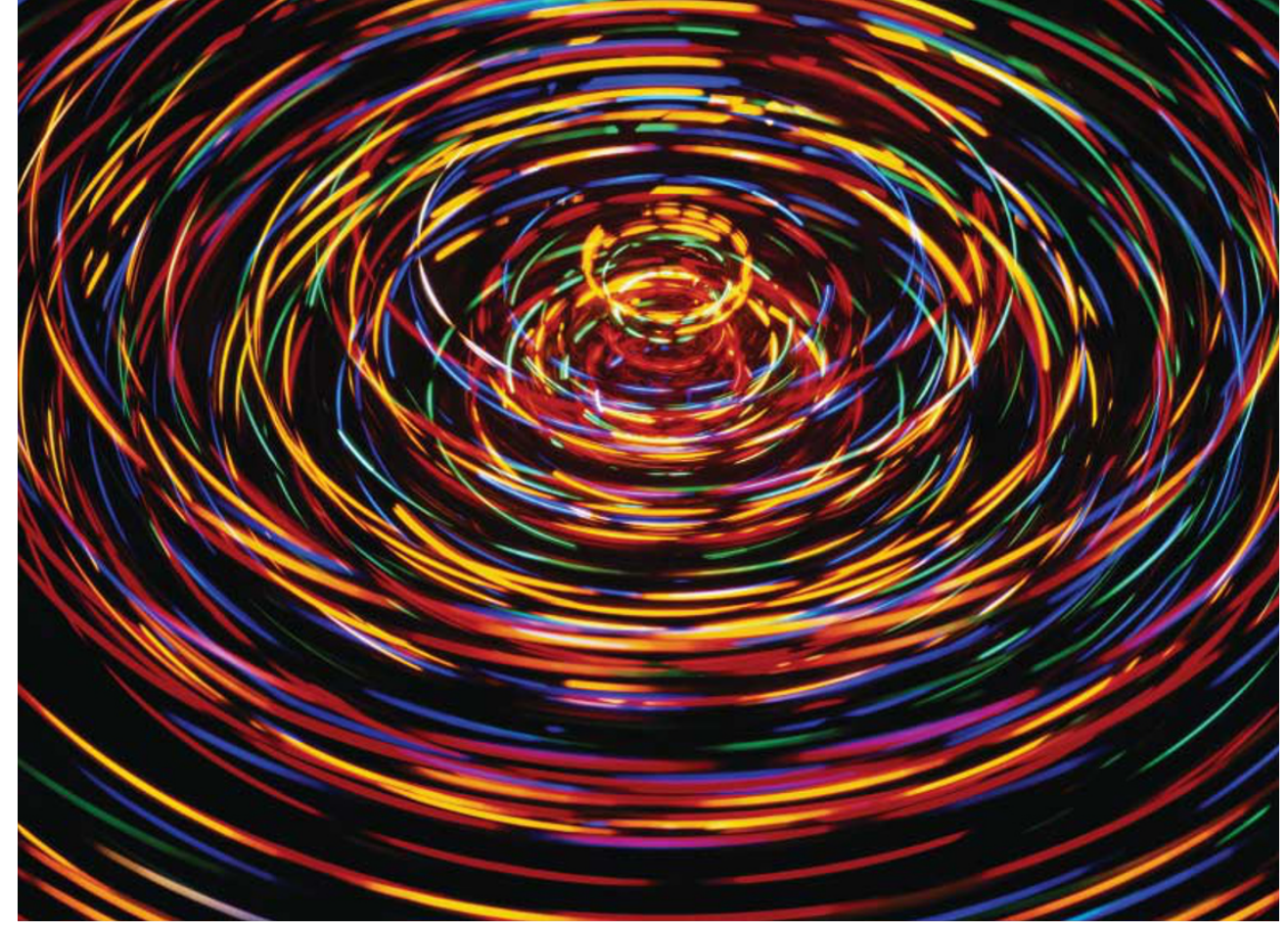

LYMPHOCYTE MIGRATION

\title{
Homing in on leukotrienes
}

To mediate an effective immune response, $\mathrm{T}$ cells must find their way to sites of infection or inflammation. Changes in T-cell homing patterns following activation are thought to result from changes in the expression of homing molecules, including adhesion molecules and chemokine receptors, however, data now show that this might not be the whole picture. Three articles in the October issue of Nature Immunology report that leukotriene $\mathrm{B}_{4}\left(\mathrm{LTB}_{4}\right)$ - an arachidonic-acidderived pro-inflammatory lipid — is also involved in T-cell recruitment.

Andrew Luster and colleagues, who generated mice deficient for the main $\mathrm{LTB}_{4}$ receptor BLT1, showed that $\mathrm{LTB}_{4}$ could direct the recruitment of $\mathrm{CD}^{+}$effector $\mathrm{T}$ cells. They showed that BLT1 was highly expressed by $\mathrm{CD}^{+}$effector T-cell subsets differentiated in vitro under $T$ helper $1\left(\mathrm{~T}_{\mathrm{H}} 1\right)$ - or $\mathrm{T}_{\mathrm{H}}$ 2-polarizing conditions and after activation in vivo. Expression of BLT1 enabled both subsets of $\mathrm{CD}^{+}$effector $\mathrm{T}$ cells to move by chemotaxis towards a $\mathrm{LTB}_{4}$ gradient, whereas naive cells were unaffected by the presence of $\mathrm{LTB}_{4}$. Both subsets of $\mathrm{CD}^{+}$effector $\mathrm{T}$ cells also adhered to endothelial cells under flow when exposed to LTB $_{4}$. They used their BLT1-deficient mice in an asthma model to show that the recruitment of early $\mathrm{CD}^{+}$and $\mathrm{CD}^{+} \mathrm{T}$ cells to the airways after aerosol challenge of previously immunized mice was dependent on the expression of BLT1.

An important source of $\mathrm{LTB}_{4}$ was shown by Vanessa Ott et al. to be activated mast cells - the sentinel cells of the tissues' early warning system. They showed that activated mast cells could induce the migration of $\mathrm{CD}^{+}$effector $\mathrm{T}$ cells through the production of $\mathrm{LTB}_{4}$. Therefore, $\mathrm{LTB}_{4}$ seems to act as a link between the activation of innate immune cells and early recruitment of adaptive immune cells.

Ulrich von Andrian's group also investigated the response of $\mathrm{CD8}^{+} \mathrm{T}$-cell subsets to $\mathrm{LTB}_{4} \cdot \mathrm{CD}^{+}$ naive, effector and central memory $\mathrm{T}$ cells have distinct migratory properties in vivo; naive and central memory $\mathrm{T}$ cells home to secondary lymphoid tissues, whereas effector T cells migrate efficiently to inflamed tissues. The authors showed that $\mathrm{CD}^{+}$effector $\mathrm{T}$ cells express high levels of BLT1, whereas $\mathrm{CD}^{+}$memory $\mathrm{T}$ cells express low levels. BLT1-expressing CD8 ${ }^{+}$effector T cells moved by chemotaxis towards $\mathrm{LTB}_{4}$, whereas naive and memory cells did not. By contrast, $\mathrm{LTB}_{4}$ induced the rapid accumulation of both effector and memory T cells, but not naive cells, in postcapillary venules by promoting the transition from rolling to firm arrest. This effect depended on signals mediated through BLT1, as cells from the BLT1-deficient mice did not arrest in response to $\mathrm{LTB}_{4}$. Using a model of peritonitis, they showed that wild-type effector cells were three times more efficient at migrating to the inflamed peritoneal cavity than BLT1-deficient effector cells, further indicating an important role for $\mathrm{LTB}_{4}-\mathrm{BLT} 1$ interactions in the trafficking of $\mathrm{CD}^{+}$effector T cells in vivo.

LucyBird

Q.) References and links

ORIGINAL RESEARCH PAPERS Tager, A. M. et al. Leukotriene $\mathrm{B}_{4}$ receptor BLT1 mediates early effector T cell recruitment. Nature Immunol. 31 August 2003 (DOI: 10.1038/ni970) | Ott, V. L. et al. Mast cell-dependent migration of effector $\mathrm{CD} 8^{+} \mathrm{T}$ cells through production of leukotriene $\mathrm{B}_{4}$. Nature Immunol. 31 August 2003 (DOI: 10.1038/ni971) | Goodarzi, K. et al. Leukotriene $B_{4}$ and BLT1 control cytotoxic effector T cell recruitment to inflamed tissues. Nature Immunol. 31 August 2003 (DOI: 10.1038/ni972) 